\title{
Effects of global warming on sex ratios in fishes
}

\author{
Benjamin Geffroy ${ }^{1} \&$ Claus Wedekind ${ }^{2}$ \\ ${ }^{1}$ MARBEC, University of Montpellier, Ifremer, IRD, CNRS, Palavas-Les-Flots, France \\ ${ }^{2}$ Department of Ecology and Evolution, Biophore, University of Lausanne, 1015 Lausanne, \\ Switzerland.
}

Correspondence: bgeffroy@ifremer.fr

\begin{abstract}
In fishes, sex is either determined by genetics, the environment, or an interaction of both. Temperature is among the most important environmental factors that can affect sex determination. As a consequence, changes in temperature at critical developmental stages can induce biases in primary sex ratios in some species. However, early sex ratios can also be biased by sex-specific tolerances to environmental stresses that may, in some cases, be amplified by changes in water temperature. Sex-specific reactions to environmental stress have been observed at early larval stages before gonad formation starts. It is therefore necessary to distinguish between temperature effects on sex determination, generally acting through the stress axis or epigenetic mechanisms, and temperature effects on sex-specific mortality. Both are likely to affect sex ratios and hence population dynamics. Moreover, in cases where temperature effects on sex determination lead to genotype-phenotype mismatches, long-term effects on population dynamics are possible. For example, temperature-induced masculinization potentially leading to the loss of $\mathrm{Y}$ chromosomes, or feminization to male-biased operational sex ratios in future generations. To date, most studies under controlled conditions conclude that if temperature affects sex ratios, elevated temperatures mostly lead to a male bias. The few studies that have been performed on wild populations seem to confirm this general trend. Recent findings suggest that transgenerational plasticity could potentially mitigate the effects of warming on sex ratios in some populations.
\end{abstract}

Keywords: Climate change, sex determination, environmental sex reversal, cortisol, methylation, sex-specific mortality 


\section{Introduction}

Sex determination in fishes is probably best seen as a threshold trait, i.e. processes that occur early in development can act as a switch that determines the cascade of processes of gonad development (Beukeboom \& Perrin, 2014). Regardless of whether these early processes have a genetic basis, they are often modifiable by external factors (Devlin \& Nagahama, 2002). Temperature is among the most important external factors that can determine or interfere with these early steps of sex differentiation (Ospina-Álvarez \& Piferrer, 2008; Baroiller \& D'Cotta, 2016).

Temperature-dependent sex determination (TSD) in fishes was probably first described in the Atlantic silverside Menidia menidia (L. 1766) where more males are produced under relatively high temperature regimes in the wild (Conover \& Kynard, 1981). Since then, many studies report an effect of temperature on sex determination in various fish families, with different levels of domestication (Devlin \& Nagahama, 2002; Ospina-Álvarez $\&$ Piferrer, 2008). This include species domesticated for many generations, like zebrafish Danio rerio (Hamilton 1822) (Uchida et al., 2004), olive flounder Paralichthys olivaceus (Schmidt 1904) (Tabata, 1995), European sea bass Dicentrarchus labrax (L. 1756) (Piferrer et al., 2005), goldfish Carassius auratus (L. 1758) (Goto-Kazeto et al., 2006), Nile tilapia Oreochromis niloticus (Trewavas 1983) (Baroiller et al., 1995), pike silverside Chirostoma estor (de Buen 1940) (Corona-Herrera et al., 2016) and African spiny catfish Clarias gariepinus (Burchell 1822) (Santi et al., 2016). But similar results were obtained for the F1 progeny of wild populations of pejerrey Odontesthes bonariensis (Valenciennes 1935) (Strüssmann et al., 1996), Nile tilapia (Bezault et al., 2007), spiny chromis damselfish Acanthochromis polyacanthus (Bleeker 1855) (Donelson \& Munday, 2015), Poecilia melanogaster (Günther 1866), 35 species of the genus Apistogramma (Römer \& Beisenherz, 1996), and even the F2 of wild atipa Hoplosternum littorale (Hancock 1828) (Hostache et al., 1995) and spiny chromis damselfish (Donelson \& Munday, 2015). Overall, this strongly suggests that thermosensitive sex determination has not evolved with domestication but is also common in the wild, perhaps with the exception of the zebrafish (Wilson et al., 2014).

Species with genetic sex determination (GSD) can have their phenotypic sex modulated by temperature as, for example, medaka Oryzias latipes (Temminck \& Schlegel 1846) (Kitano et al., 2012), sockeye salmon Oncorhynchus nerka (Walbaum 1792) (Craig et al., 1996; Azuma et al., 2004), rainbow trout Oncorhynchus mykiss (Walbaum 1792)(Valdivia et al., 2014) and sablefish Anoplopoma fimbria (Pallas 1814) (Huynh et al., 2019). An interesting observation in this context is that juveniles of Nile tilapia or African catfish (both species with GSD) sometimes seem actively to seek warmer temperatures around the time of sex differentiation in order to develop into males (Santi et al., 2017; Nivelle et al., 2019). Such temperature-induced genotype-phenotype mismatches can produce interesting long-term effects on demography, as discussed below.

In nearly all cases, high temperatures lead to a higher ratio of males in species with TSD, or induce masculinization in species where GSD can be overruled by temperature. It therefore seems that male bias at high temperature is a rule in fishes. This suggests that producing males may often be adaptive in harsh conditions (Geffroy \& Douhard, 2019). Different hypotheses have been proposed in this context, including higher migration propensity and quicker maturation, leading to a greater relative fitness for males than females in unpredictable environments (Geffroy \& Douhard, 2019). However, female bias at high temperatures are common in other taxa (e.g. Janzen 1994), and there are at least two examples of temperature-related female bias in fishes, in sockeye salmon (Craig et al., 1996) and channel catfish Ictalurus punctatus (Rafinesque 1818) (Patiño et al., 1996). Patino et al. (1996) could not exclude sex-specific mortality as confounding factor in their study but they argued that such selective mortality was unlikely to have produced the observed effects 
because there were no sex-ratio biases in low-temperature treatment groups, despite significant mortality.

Temperature effects on sex ratios can be a threat to natural populations. Here we discuss how and when changed temperature regimes affect primary and operational sex ratio in fishes, and we outline possible short-term and long-term consequences of temperatureinduced sex ratio biases.

\section{Types of temperature effects on sex determination}

So far, most studies investigating temperature effects on sex ratios have concentrated on species within the Perciformes, a comparatively young order of fishes. The phylogenetic tree of teleost fishes started, however, about 300 to 360 million years ago in the Carboniferous. Many orders have been evolutionarily separated by hundreds of millions of years, which may explain why fishes exhibit such great diversity in sex determination and sex differentiation (Wang et al., 2018). The Cypriniformes, Salmoniformes, and Perciformes, for example, have been separated for over 200 million years each (Near et al., 2012). Much research has been done on these orders because they are well represented in aquaculture (Baroiller \& D'Cotta, 2001). Each of these orders includes species where temperature effects on sex determination have been described, and species where no such temperature effects could be found (Figure 1).

Figure 2 illustrates the range of possible temperature effects on sex ratios. Masculinization at high temperature (scenarios B2 and B3 in Figure 2) is the commonest response observed so far, but there are potential examples of other responses (Figure 2), and further patterns cannot currently be excluded. The patterns are often not very strong (see, for example, the Supplementary Table 1 of Ospina-Alvarez and Pifferer (2008). Moreover, there is often significant variation among families, as in zebrafish (Ribas et al., 2017), African catfish (Santi et al., 2016), and Nile tilapia (Baroiller \& D'Cotta, 2001; Nivelle et al., 2019), and there can be significant variation among experimental runs, as observed in European sea bass (Vandeputte \& Piferrer, 2018). Some of this variation could, however, be due to sexspecific mortality at very early stages (see discussion below).

Most studies on temperature effects on sex ratio have been performed under laboratory conditions. A recent study on the southern flounder Paralichthys lethostigma (Jordan \& Gilbert 1884) combined laboratory experiments with field observations (Honeycutt et al., 2019). This is a species where temperature extremes (warm and cold) had previously been reported to induce masculinization (Luckenbach et al., 2003) (C2 in Figure 2). Honeycutt et al. (Honeycutt et al., 2019) used gonadal expression of sex-specific markers to determine the phenotypic sex of juveniles caught at different locations along the east coast of North Carolina (USA) and observed increasingly male-biased sex-ratios with increasing water temperatures. These temperature effects were then largely confirmed under controlled conditions in the laboratory (Honeycutt et al., 2019). In another study system, however, laboratory experiments by Pompini et al. (2013) did not confirm the link between water temperatures and sex ratios that Wedekind et al. (2013) had found in a wild population of grayling Thymallus thymallus (L. 1758). The authors concluded that the link between sex ratio and temperature in the wild is more likely caused by sex-specific mortality (see below) than by temperature effects on sex determination, a conclusion that was further supported by the first description of the sex determining locus in this species (Yano et al., 2013).

It is important to note that climate change does not necessarily lead to increased temperatures during the critical stages of sex differentiation. Elevated summer temperatures can, for example, delay spawning of brook trout Salvelinus fontinalis (Mitchill 1814) in autumn or winter (Warren et al., 2012), and elevated winter temperatures can advance spawning in spring for grayling (Wedekind \& Küng, 2010). In the latter case, 40 years of 
continuous temperature measurements revealed a somewhat counterintuitive effect, namely that the observed shift of spawning season (by over 3 weeks over a few decades) caused increasingly colder temperature environments for larvae around hatching, i.e. around a time that has been found to be critical for sex determination in other species (Devlin \& Nagahama, 2002). This is because climate change seemed to cause temperatures to rise increasingly more slowly in early than in late spring in the habitat of the study population.

In conclusion, even if global change typically leads to warmer temperatures and even if most examples in fishes indicate that masculinization is more likely than feminization at higher temperatures, global change could, in some cases, also induce feminization (e.g. by exposure to colder temperatures at critical developmental stages because of temporal shifts in important life history events). Therefore, the likely effects of both, masculinization and feminization, need to be considered.

\section{Physiology of temperature effects on sex determination}

\subsection{Primary sex ratios in lower vertebrates}

The term "primary sex ratio" is usually defined as sex ratio at the time of conception, but this definition excludes many lower vertebrates because it implies that sex is only genetically determined. In fishes with environmental influence on sex determination, i.e. with either environmental sex determination or environmental sex reversal (environmental factors overruling genetic factors), the primary sex ratio can only be determined at a time when the decisive processes that occur early in development have set the path to the development of testes or ovaries. It is not surprising that at this time, typically during embryogenesis and/or early larval stages (Devlin \& Nagahama, 2002), the sexes show sex-specific gene expression (Geffroy et al., 2016; Maitre et al., 2017). At that time, they also show sex-specific reactions to environmental stress such as, for example, exposure to exogenous sex hormones at ecologically relevant concentrations (Selmoni et al., 2019).

\subsection{Cortisol}

The link between environmental variables (particularly high temperature and fish density) and the stress axis (through the production of cortisol) has been established as an important factor influencing sex determination in various fish species, typically resulting in masculinization (Geffroy \& Douhard, 2019). Incubating rainbow trout eggs in cortisol leads to the development of testes (van den Hurk \& van Oordt, 1985), and cortisol administration induces masculinization in three-spotted wrasse Halichoeres trimaculatus (Quoy \& Gaimard 1834) (Nozu \& Nakamura, 2015) and orange-spotted grouper Epinephelus coioides (Hamilton 1822) (Chen et al., 2020). Cortisol is also expected to play a crucial role in sex-change of various sequential hermaphrodite species (Goikoetxea et al., 2017; Olivotto \& Geffroy, 2017). A brief exposure (minutes to hours) to a temperature that is outside the thermal preference of a fish can elicit an increase in cortisol production (e.g. Cockrem et al., 2019). Chronic exposure to high temperatures can also lead to higher basal concentrations of cortisol (Madaro et al., 2018) although it is not yet established whether this represents a state of physiological stress (Schreck \& Tort, 2016) with higher routine metabolic rate and enzyme activities (see review of Alfonso et al. 2020 in this special issue).

If it is indeed mainly stress that affects sex differentiation, temperature would play an indirect role in some fishes. That is, stressful temperatures would induce the production of cortisol and then typically induce male development, as exemplified in the pejerrey (Hattori et $a l ., 2009)$. To date, most of our knowledge on the underlying mechanisms has been gathered from three species: the medaka, the pejerrey, and the olive flounder. Four distinct and direct mechanisms linking temperature-induced stress and sex have been demonstrated. Two involved a down-regulation of feminizing genes (cyp19ala and fshr) while the two others 
involved an up-regulation of masculinization genes (dmrtla and hsd1 1b2) (Figure 3). For the former, the complex formed by cortisol and its receptor the glucocorticoid receptor (CORT/GR), bound to a specific promoter zone (glucocorticoid response element, GRE) of the gene encoding gonadal aromatase (cyp19ala), the enzyme that converts androgens into estrogens (Guiguen et al., 2010), as demonstrated in the olive flounder (Yamaguchi et al., 2010). This results in down-regulation of cyp 19ala, which in turn impedes estrogen production and leads to an accumulation of testosterone in the indifferentiated gonad. Another mechanism involves the follicle stimulating hormone receptor $f s h r$. In medaka, the CORT/GR can bind to a GRE in the promotor region of $f_{s h}$ (Hayashi et al., 2010), which may lead to an imbalance between androgens and estrogens.

More recently, in vitro experiments showed that CORT/GR stimulates expression of the autosomal dmrtla (a duplicate of dmrtlbY, the master sex-determining gene) in XX medaka, potentially explaining masculinisation of these genetic females (Adolfi et al., 2019). Interestingly, disrupting the cortisol synthesis pathway using CRISPR/Cas9 technology targeting corticotropin-releasing factor $\operatorname{crf}$ (released by the hypothalamus at the beginning of the cortisol synthesis cascade) inhibited sex reversal in XX medaka reared at high temperature (Cortés et al., 2019).

It should be emphasized that the synthesis of 11-oxygenated androgens is related to that of cortisol because their synthesis and inactivation involves the same steroidogenic machinery. The last step of cortisol synthesis is performed by 11- $\beta$-hydroxylase (CYP11B) but this enzyme is also responsible for the 11-hydroxylation of testosterone into $11-\beta-\mathrm{OH}-$ testosterone (Borg, 1994). The catabolization of cortisol into cortisone (its biologically inactive metabolite) is performed by $11 \beta$-hydroxysteroid dehydrogenase (11- $\beta$-HSD) that is also responsible for conversion of 11- $\beta$-OH-testosterone into 11-ketotestosterone (11-KT). This has led some authors to propose that the production of biologically active androgens (e.g. 11-KT) is only a collateral outcome of high production of $11-\beta-\mathrm{HSD}$, to deal with the elevated production of cortisol at warm temperatures (Fernandino et al., 2013). Indeed, in vitro treatment of testes of pejerrey with cortisol caused an up-regulation of 11-KT synthesis, through activation of 11- $\beta$-HSD (Fernandino et al., 2012). Overall, although our understanding of the mechanisms involved in temperature-stress-sex regulation is increasing, it is not yet clear why binding of CORT/GR to GREs can elicit either an up- or a downregulation of glucocorticoid-responsive genes.

\subsection{Epigenetics}

Epigenetics can be defined as "... the study of phenomena and mechanisms that cause chromosome-bound, heritable changes to gene expression that are not dependent on changes in DNA sequence" (Deans \& Maggert, 2015). With regard to temperature-induced masculinization of gonochoristic species, most of our knowledge of epigenetics is from studies analyzing methylation of promoter regions of various key sex differentiation genes (see Piferrer et al., 2019; Ortega-Recalde et al., 2020 for review). A common mechanism appears to be conserved in many species that are sensitive to temperature. That is, exposure to warmer temperature consistently increases DNA methylation of the cyp 19ala promoter, resulting in decreasing expression of cyp19ala in phenotypic (and possibly sex-reversed) males of European sea bass (Navarro-Martín et al., 2011), in ZW pseudomales of the tongue sole Cynoglossus semilaevis (Liu et al., 2019), in XX pseudomales of the Nile tilapia (Wang et al., 2019) and in XX pseudomales of the olive flounder (Wen et al., 2014). Many other sexspecific genes, particularly $d m r t 1$ (Wen et al., 2014), appear to be differentially methylated after exposure to high temperatures, which warrants further investigation (Piferrer et al., 2019). While various potential processes have been revealed for cortisol-induced masculinization, we do not yet know the mechanisms by which the temperature induces 
specific methylation of target genes (Piferrer et al., 2019). In reptiles with TSD, a calcium and redox $(\mathrm{CaRe})$-mediated signal has recently been proposed as a "cellular sensor" that links environment factors (e.g. temperature) to epigenetic processes (Castelli et al. 2020), which is an interesting avenue of investigation for fishes.

Epigenetic modifications can be responsible for transgenerational plasticity that allows fishes to rapidly modulate sex-determination in response to prevailing thermal conditions (Grossen et al. 2011). For instance, exposing spiny chromis damselfish to elevated temperatures during development causes male-biased sex ratios, but when both parents and F1 are reared at those elevated temperatures, no such bias is observed (Donelson \& Munday, 2015). In a domesticated strain of zebrafish where sex determination is under genetic and environmental influence, parents exposed to warm temperatures produced more male offspring in the unexposed F1 but these temperature effects varied among families, and the sex ratio of the unexposed F2 was not affected by the warm exposure of their grandparents (Valdivieso et al., 2020).

\section{Sex-specific mortality}

Population sex ratios are a product of primary sex ratios, sex-specific life histories, and sexspecific mortality (Figure 4). The latter can, in principle, occur at any life stage. If it happens during early developmental stages, it may sometimes be difficult to distinguish from environmental effects on sex determination. As a consequence, any kind of mortality should be seen as a potentially confounding factor in studies of environmental effects on sex determination.

The development of sex-linked genetic markers (Yano et al., 2013) has permitted investigation of sex-linked mortality at very early developmental stages within various species. Moran et al. (2016), for example, used such markers in brown trout Salmo trutta (L. 1758) families, to gain evidence of sex-specific mortality during embryo and early larval stages in some of families but not others. Such mortality may typically be induced by symbiotic microbial communities (Wilkins et al., 2015a) whose composition varies with temperature (Wilkins et al., 2015c) but also with embryo age (Wilkins et al., 2015b), embryo genetics (Wilkins et al., 2016), and maternal environmental effects, e.g. egg carotenoids content (Wilkins et al., 2017). Such family-specific stress environments are likely to cause family- and sex-specific reactions that, on a population level, may cancel each other out. If so, sex-specific mortalities would easily be missed if studied in populations rather than families. In Nile tilapia (with a XX/XY system), a role for sex-specific mortality was ruled out by i) raising $\mathrm{XX}$ progenies at high temperature, which resulted in the production of males (no female mortality, but rather a sex-reversal) and ii) identifying XX males in temperature treated groups in many different experiments (Baroiller et al., 2009).

Not much is known about the physiology of sex-specific mortality at very early stages. However, the sexes often differ significantly in their life history at later developmental stages and such sex-specific strategies are likely to induce sex-specific sensitivities to certain stress factors at certain times. Sex differences in life history and behavior are often most profound shortly before and during spawning season, and the factors that induce sex-specific mortality can be diverse, including predation and pathogens. The relevance of these factors often depends on water temperature, e.g. the virulence of Tetracapsuloides bryosalmonae that causes proliverative kidney disease in many salmonids is temperature dependent (Bettge et al., 2009). As a consequence, changes in thermal regimes can influence sex ratios around spawning time.

Sex differences in life history are easily overlooked if they are expressed early in life, e.g. before or around gonad formation. Such sex differences can, however, lead to sexspecific larval or juvenile mortality in response to environmental stressors, many of which 
may interact with temperature. Wedekind et al. (2013) compared water temperatures with adult sex ratios of wild grayling at their spawning sites in a pre-Alpine region, over a period of about 40 years, and found a significant male-biased sex ratio since the early 1990s. This may be a contributing factor to declines in these populations (Wedekind \& Küng, 2010). The bias started five years after a significant shift in average water temperature, which coincided with a temperature regime shift in Europe and elsewhere (Reid et al., 2016). Interestingly, this five-year gap between temperature change and change in sex ratio corresponds well with the average age of the fish that were sampled, namely 5 years. Pompini et al. (2013) therefore tested experimentally whether the temperature change could have influenced sex determination in the population. They found no evidence for such temperature effects and therefore concluded that sex-specific mortality during the first year of life is the most parsimonious explanation for the shifted sex ratio. Maitre et al. (2017) then used sex-linked molecular markers to study gonad development of genetic males and females, to find marked differences in the timing of gonad development: females start during their first summer (i.e. at a time when the natural population is exposed to increasingly higher water temperatures) whereas males grow faster during these months and only start developing testes in autumn, after the warm period. Such different life histories could potentially cause female-biased juvenile mortality linked to climate change.

Sex differences in the timing of gonad development have also been found in channel catfish (Patiño et al., 1996): when reared at $27^{\circ} \mathrm{C}$, females and males started sex differentiation around 20 and 100 days after fertilization, respectively, and sex ratio was essentially balanced. When reared at $34^{\circ} \mathrm{C}$, however, a significant female-bias was observed at 102 days after fertilization. Patino et al. (1996) could not resolve whether the female bias at warmer temperature was due to feminization of genetic males, sex-biased mortality, or a combination of both. If sex-biased mortality played a role, males would be more susceptible to warmer temperature in this species, early gonad formation would not necessarily make one sex more susceptible to higher temperature than the other.

\section{Sex-specific fertility}

Changes in temperature regimes may not only affect life histories and mortality but also fertility, by affecting gamete number and viability, as demonstrated in various taxa including some fishes (Walsh et al., 2019). Temperature effects on fertility are likely to be sex-specific, especially in ectotherms (Iossa, 2019). Such sex-specific effects may be critical for effects of climate change on population viability. Information about population sex ratios may then be inadequate and operational sex ratios, i.e. the ratio of males and females that are ready to mate, could instead be used to evaluate the consequences of global warming for the two sexes and overall population dynamics.

Iossa (2019) argues that male fertility is typically less resilient to temperature-induced stress than female fertility, but stresses that sex differences may well be taxon-specific. The physiology of temperature effects on fertility of the two sexes therefore needs to be studied within various taxa. Heritability of susceptibility to such temperature effects may induce rapid evolution and hence local adaptation (Grossen et al., 2011).

\section{Consequences for population dynamics}

Temperature effects on sex ratios can potentially induce both immediate and long-term effects on population dynamics. One potential immediate effect is a change in recruitment rates. Obviously, if egg numbers limit population grow, male-biased sex ratios can cause or reveal a reduction of absolute female numbers that may cause a population decline, as has been proposed for temperate eels (Geffroy \& Bardonnet, 2016). The male bias in the grayling population studied by Wedekind et al. (2013) seems to provide a good example. The 
population is fully protected, water quality in their habitat is high and no environmental factor can, so far, be linked to the observed population decline except the significant increase in water temperature over recent decades. In other species like some cichlids (e.g. Sarotherodon melanotheron) (Kishida \& Specker, 2000) or seahorses (Stölting \& Wilson, 2007), immediate negative effects on recruitment rates might also result from male parental care and protective incubation, which limits population growth so that a female-biased sex ratio could have drastic consequences for the population.

There are two main forms of potential long-term consequences of biased sex ratios for population dynamics. One could result from temperature-induced sex reversal (Figure 4). Such early modifications of sex determination do usually not create significant long-lasting effects on growth and survival (Senior et al., 2012, 2016) but they can create genotypephenotype mismatches with impacts on population demography. For example, if sex determination is male dominant $(\mathrm{XX} / \mathrm{XY})$, continuous masculinization can drive $\mathrm{Y}$ chromosomes to extinction and hence change the sex determination system of a population from GSD to ESD (Kanaiwa \& Harada, 2008; Grossen et al., 2011). The maintenance of the two sexes would then depend upon environmental masculinization. Analogous dynamics are possible if sex determination is female dominant (ZZ/ZW) (Schwanz et al., 2020).

Populations can then rapidly go extinct if the environmental pressure that causes the sex reversal ceases (Cotton \& Wedekind, 2009). On the other hand, if climate change leads to a female-biased sex ratio, either because of direct effects of high temperature on physiology or because of changed environments due to shifts in the timing of spawning or other lifehistory events (as discussed above), the resulting XY females are expected to produce malebiased families when reproducing with wild-type XY males: $25 \%$ of the $\mathrm{F} 1$ will be XX, $50 \%$ $\mathrm{XY}$, and 25\% YY. The latter genotypes are usually viable in fishes (Senior et al., 2012).

Without further feminization, the XY and YY genotypes will be males, so that the family sex ratio of such sex-reversed females will be strongly male-biased. Moreover, a third of these males (i.e. the YY males) would only produce XY offspring in the F2 generation.

Environmental feminization would therefore be expected to first create female-biased sex ratios but then male-biased sex ratios in subsequent generations. Continuous feminization over several generations could amplify the sex biases and hence threaten population viability, especially if it involves feminization of YY individuals (Bókony et al., 2017; Wedekind, 2017).

The other form of possible long-term consequences for population dynamics of biased sex ratios derives from the effects that unequal sex ratios have on effective population size $\left(\mathrm{N}_{\mathrm{e}}\right)$. This effect can be estimated as

$$
\mathrm{N}_{\mathrm{e}}=4 \mathrm{~N}_{\mathrm{m}} \mathrm{N}_{\mathrm{f}} /\left(\mathrm{N}_{\mathrm{m}}+\mathrm{N}_{\mathrm{f}}\right)
$$

based on male and female numbers $\left(\mathrm{N}_{\mathrm{m}}\right.$ and $\mathrm{N}_{\mathrm{f}}$, respectively) (Hartl, 1988). Figure 5 illustrates how biased sex ratios affect $\mathrm{N}_{\mathrm{e}}$. A declining $\mathrm{N}_{\mathrm{e}}$ signifies a loss of genetic diversity within a population and hence a reduction in the potential to adapt to changing environments. Since human activities are causing various types of rapid environmental change, a loss of evolutionary potential could be a major threat to population resilience (Hendry et al., 2017). Another potential threat that is linked to a reduction of genetic diversity within populations is co-evolving pathogens, whose virulence can increase in response to low genetic diversity in their hosts (e.g. Kubinak et al., 2012). Lehnert et al., (2019) reported a strong association between the decline of more than half of 172 Atlantic salmon Salmo salar (L. 1758) populations over recent decades and the decline of their respective $\mathrm{N}_{\mathrm{e}}$. A strong correlate of these declines seemed to be increased winter temperatures and their effects on development of 
early developmental stages, but it remains unclear whether and how these temperature changes affected sex ratios.

\section{Conclusion}

Based upon many laboratory studies and a few investigations in the field, the general patterns that emerge are that, if climate change affects population sex ratios in fish, (i) malebiased population sex ratios seem generally more likely than female-biased; (ii) sex ratios can differ from generation to generation, due to factors such as transgenerational plasticity or the demographic effects of phenotype-genotype mismatches that sex reversal can create; (iii) there can be significant family effects on sex ratios, which could mask environmental effects on sex determination at a population level, and (iv) epigenetic and stress-related mechanisms probably play a role in responses to warming. Another general trend is that, if sex ratios are affected by temperature, the reactions seem similar in wild and domesticated species. Given the limited studies on wild populations, however, it is difficult to predict how global warming will affect the sex ratio of a given population. There are various factors that determine whether climate change causes either increased or decreased water temperatures at developmental stages that are critical for sex determination in a given fish population and species. Changed temperature regimes may affect the timing of spawning and, hence, the temperature regime during earlier developmental stages. Coupled with associated changes in day length (due to a shift in the timing of events) or changes in other environmental factors (e.g. $\mathrm{pH}$ ), this could influence embryo and larval development at critical stages. Another important challenge for future field studies will be to separate environmental effects on sex determination from environmental effects on sex-specific mortality.

\section{Acknowledgements}

We thank two reviewers and David J. McKenzie for constructive comments. BG is supported by the European Maritime and Fisheries Fund (3S, Seabass Sex and Stress, grant 4320175237), CW by the Swiss National Science Foundation (SNF 31003A_125396; SNF 31003A_182265).

\section{Bibliography}

Adolfi, M. C., Fischer, P., Herpin, A., Regensburger, M., Kikuchi, M., Tanaka, M., \& Schartl, M. (2019). Increase of Cortisol Levels after Temperature Stress Activates Dmrt1a Causing Female-to-Male Sex Reversal and Reduced Germ Cell Number in Medaka. Molecular Reproduction and Development, 86, $1405-1417$.

Azuma, T., Takeda, K., Doi, T., Muto, K., Akutsu, M., Sawada, M., \& Adachi, S. (2004). The Influence of Temperature on Sex Determination in Sockeye Salmon Oncorhynchus Nerka. Aquaculture, 234, 461473.

Baroiller, J. F., \& D'Cotta, H. (2001). Environment and Sex Determination in Farmed Fish. Comparative Biochemistry and Physiology Part C: Toxicology \& Pharmacology, 130, 399-409.

Baroiller, J. F., D'Cotta, H., Bezault, E., Wessels, S., \& Hoerstgen-Schwark, G. (2009). Tilapia Sex Determination: Where Temperature and Genetics Meet. Comparative Biochemistry and Physiology Part A: Molecular \& Integrative Physiology, 153, 30-38.

Baroiller, J. F., Chourrout, D., Fostier, A., \& Jalabert, B. (1995). Temperature and Sex Chromosomes Govern Sex Ratios of the Mouthbrooding Cichlid Fish Oreochromis Niloticus. Journal of Experimental Zoology, 273, 216-223.

Baroiller, J.-F., \& D'Cotta, H. (2016). The Reversible Sex of Gonochoristic Fish: Insights and Consequences. Sexual Development, 10, 242-266.

Bettge, K., Segner, H., Burki, R., Schmidt-Posthaus, H., \& Wahli, T. (2009). Proliferative Kidney Disease (PKD) of Rainbow Trout: Temperature- and Time-Related Changes of Tetracapsuloides Bryosalmonae DNA in the Kidney. Parasitology, 136, 615-625.

Beukeboom, L. W., \& Perrin, N. (2014). The Evolution of Sex Determination. Oxford University Press. Bezault, E., Clota, F., Derivaz, M., Chevassus, B., \& Baroiller, J.-F. (2007). Sex Determination and 
Temperature-Induced Sex Differentiation in Three Natural Populations of Nile Tilapia (Oreochromis Niloticus) Adapted to Extreme Temperature Conditions. Aquaculture, 272, S3-S16.

Bókony, V., Kövér, S., Nemesházi, E., Liker, A., \& Székely, T. (2017). Climate-Driven Shifts in Adult Sex Ratios via Sex Reversals: The Type of Sex Determination Matters. Philosophical Transactions of the Royal Society B: Biological Sciences, 372, 20160325.

Borg, B. (1994). Androgens in Teleost Fishes. Comparative Biochemistry and Physiology Part C: Pharmacology, Toxicology and Endocrinology, 109, 219-245.

Castelli, M. A., Whiteley, S. L., Georges, A., \& Holleley, C. E. Cellular Calcium and Redox Regulation: The Mediator of Vertebrate Environmental Sex Determination? Biological Reviews, n/a.

Chen, J., Peng, C., Yu, Z., Xiao, L., Yu, Q., Li, S., ... Zhang, Y. (2020). The Administration of Cortisol Induces Female-to-Male Sex Change in the Protogynous Orange-Spotted Grouper, Epinephelus Coioides. Frontiers in Endocrinology, 11.

Cockrem, J. F., Bahry, M. A., \& Chowdhury, V. S. (2019). Cortisol Responses of Goldfish (Carassius Auratus) to Air Exposure, Chasing, and Increased Water Temperature. General and Comparative Endocrinology, 270, 18-25.

Corona-Herrera, G. A., Tello-Ballinas, J. A., Hattori, R. S., Martínez-Palacios, C. A., Strüssmann, C. A., Cárdenas-Reygadas, R. R., \& Martínez-Chávez, C. C. (2016). Gonadal Differentiation and Temperature Effects on Sex Determination in the Freshwater Pike Silverside Chirostoma Estor Jordan 1880. Environmental Biology of Fishes, 99, 463-471.

Cortés, D. C. C., Padilla, L. F. A., Langlois, V. S., Somoza, G. M., \& Fernandino, J. I. (2019). The Central Nervous System Acts as a Transducer of Stress-Induced Masculinization through CorticotropinReleasing Hormone B. Development, 146.

Cotton, S., \& Wedekind, C. (2009). Population Consequences of Environmental Sex Reversal. Conservation Biology, 23, 196-206.

Craig, J. K., Foote, C. J., \& Wood, C. C. (1996). Evidence for Temperature-Dependent Sex Determination in Sockeye Salmon (Oncorhynchus Nerka). Canadian Journal of Fisheries and Aquatic Sciences, 53, 141-147.

Deans, C., \& Maggert, K. A. (2015). What Do You Mean, "Epigenetic"? Genetics, 199, 887-896.

Devlin, R. H., \& Nagahama, Y. (2002). Sex Determination and Sex Differentiation in Fish: An Overview of Genetic, Physiological, and Environmental Influences. Aquaculture, 208, 191-364.

D.o, C. (1984). Adaptive Significance of Temperature-Dependent Sex Determination in a Fish [Atlantic Silverside, Menidia Menidia]. American Naturalist.

Donelson, J. M., \& Munday, P. L. (2015). Transgenerational Plasticity Mitigates the Impact of Global Warming to Offspring Sex Ratios. Global Change Biology, 21, 2954-2962.

Fernandino, J. I., Hattori, R. S., Kishii, A., Strüssmann, C. A., \& Somoza, G. M. (2012). The Cortisol and Androgen Pathways Cross Talk in High Temperature-Induced Masculinization: The 11ßHydroxysteroid Dehydrogenase as a Key Enzyme. Endocrinology, 153, 6003-6011.

Fernandino, J. I., Hattori, R. S., Moreno Acosta, O. D., Strüssmann, C. A., \& Somoza, G. M. (2013). Environmental Stress-Induced Testis Differentiation: Androgen as a by-Product of Cortisol Inactivation. General and Comparative Endocrinology, 192, 36-44.

Geffroy, B., \& Bardonnet, A. (2016). Sex Differentiation and Sex Determination in Eels: Consequences for Management. Fish and Fisheries, 17, 375-398.

Geffroy, B., Guilbaud, F., Amilhat, E., Beaulaton, L., Vignon, M., Huchet, E., ... Bardonnet, A. (2016). Sexually Dimorphic Gene Expressions in Eels: Useful Markers for Early Sex Assessment in a Conservation Context. Scientific Reports, 6.

Geffroy, B., \& Douhard, M. (2019). The Adaptive Sex in Stressful Environments. Trends in Ecology \& Evolution, 34, 628-640.

Goikoetxea, A., Todd, E. V., \& Gemmell, N. J. (2017). Stress and Sex: Does Cortisol Mediate Sex Change in Fish? Reproduction, 154, R149-R160.

Goto-Kazeto, R., Abe, Y., Masai, K., Yamaha, E., Adachi, S., \& Yamauchi, K. (2006). TemperatureDependent Sex Differentiation in Goldfish: Establishing the Temperature-Sensitive Period and Effect of Constant and Fluctuating Water Temperatures. Aquaculture, 254, 617-624.

Grossen, C., Neuenschwander, S., \& Perrin, N. (2011). Temperature-Dependent Turnovers in SexDetermination Mechanisms: A Quantitative Model. Evolution, 65, 64-78.

Guiguen, Y., Fostier, A., Piferrer, F., \& Chang, C.-F. (2010). Ovarian Aromatase and Estrogens: A Pivotal Role for Gonadal Sex Differentiation and Sex Change in Fish. General and Comparative Endocrinology, 165, 352-366. 
Hartl, D. L. (1988). A Primer of Population Genetics. A primer of population genetics.

Hattori, R. S., Fernandino, J. I., Kishii, A., Kimura, H., Kinno, T., Oura, M., ... Watanabe, S. (2009). Cortisol-Induced Masculinization: Does Thermal Stress Affect Gonadal Fate in Pejerrey, a Teleost Fish with Temperature-Dependent Sex Determination? PLoS ONE, 4, e6548.

Hayashi, Y., Kobira, H., Yamaguchi, T., Shiraishi, E., Yazawa, T., Hirai, T., ... Kitano, T. (2010). High Temperature Causes Masculinization of Genetically Female Medaka by Elevation of Cortisol. Molecular Reproduction and Development, 77, 679-686.

Hendry, A. P., Gotanda, K. M., \& Svensson, E. I. (2017). Human Influences on Evolution, and the Ecological and Societal Consequences. Philosophical Transactions of the Royal Society B: Biological Sciences, 372, 20160028.

Honeycutt, J. L., Deck, C. A., Miller, S. C., Severance, M. E., Atkins, E. B., Luckenbach, J. A., ... Godwin, J. (2019). Warmer Waters Masculinize Wild Populations of a Fish with Temperature-Dependent Sex Determination. Scientific Reports, 9, 1-13.

Hostache, G., Pascal, M., \& Tessier, C. (1995). Influence de La Température d'incubation Sur Le Rapport Mâle: Femelle Chez l'atipa, Hoplosternum Littorale Hancock (1828). Canadian Journal of Zoology, 73, 1239-1246.

van den Hurk, R., \& van Oordt, P. G. W. J. (1985). Effects of Natural Androgens and Corticosteroids on Gonad Differentiation in the Rainbow Trout, Salmo Gairdneri. General and Comparative Endocrinology, 57, 216-222.

Huynh, T. B., Fairgrieve, W. T., Hayman, E. S., Lee, J. S. F., \& Luckenbach, J. A. (2019). Inhibition of Ovarian Development and Instances of Sex Reversal in Genotypic Female Sablefish (Anoplopoma Fimbria) Exposed to Elevated Water Temperature. General and Comparative Endocrinology, 279, $88-98$.

Iossa, G. (2019). Sex-Specific Differences in Thermal Fertility Limits. Trends in Ecology \& Evolution, 34, 490-492.

Kanaiwa, M., \& Harada, Y. (2008). Collapse of One-Locus Two-Allele Sex Determining System by Releasing Sex-Reversed Hatchery Fish. Reviews in Fisheries Science, 16, 296-302.

Kishida, M., \& Specker, J. L. (2000). Paternal Mouthbrooding in the Black-Chinned Tilapia, Sarotherodon Melanotheron (Pisces: Cichlidae): Changes in Gonadal Steroids and Potential for Vitellogenin Transfer to Larvae. Hormones and Behavior, 37, 40-48.

Kitano, T., Hayashi, Y., Shiraishi, E., \& Kamei, Y. (2012). Estrogen Rescues Masculinization of Genetically Female Medaka by Exposure to Cortisol or High Temperature. Molecular Reproduction and Development, 79, 719-726.

Kubinak, J. L., Ruff, J. S., Hyzer, C. W., Slev, P. R., \& Potts, W. K. (2012). Experimental Viral Evolution to Specific Host MHC Genotypes Reveals Fitness and Virulence Trade-Offs in Alternative MHC Types. Proceedings of the National Academy of Sciences, 109, 3422-3427.

Lehnert, S. J., Kess, T., Bentzen, P., Kent, M. P., Lien, S., Gilbey, J., ... Bradbury, I. R. (2019). Genomic Signatures and Correlates of Widespread Population Declines in Salmon. Nature Communications, 10, $1-10$.

Liu, J., Liu, X., Jin, C., Du, X., He, Y., \& Zhang, Q. (2019). Transcriptome Profiling Insights the Feature of Sex Reversal Induced by High Temperature in Tongue Sole Cynoglossus Semilaevis. Frontiers in Genetics, 10.

Luckenbach, J. A., Godwin, J., Daniels, H. V., \& Borski, R. J. (2003). Gonadal Differentiation and Effects of Temperature on Sex Determination in Southern Flounder (Paralichthys Lethostigma). Aquaculture, $216,315-327$.

Madaro, A., Folkedal, O., Maiolo, S., Alvanopoulou, M., \& Olsen, R. E. (2018). Effects of Acclimation Temperature on Cortisol and Oxygen Consumption in Atlantic Salmon (Salmo Salar) Post-Smolt Exposed to Acute Stress. Aquaculture, 497, 331-335.

Maitre, D., Selmoni, O. M., Uppal, A., Marques da Cunha, L., Wilkins, L. G. E., Roux, J., ... Wedekind, C. (2017). Sex Differentiation in Grayling (Salmonidae) Goes through an All-Male Stage and Is Delayed in Genetic Males Who Instead Grow Faster. Scientific Reports, 7, 1-11.

Middaugh, D. P., \& Hemmer, M. J. (1987). Influence of Environmental Temperature on Sex-Ratios in the Tidewater Silverside, Menidia Peninsulae (Pisces: Atherinidae). Copeia, 1987, 958-964.

Morán, P., Labbé, L., \& Garcia de Leaniz, C. (2016). The Male Handicap: Male-Biased Mortality Explains Skewed Sex Ratios in Brown Trout Embryos. Biology Letters, 12, 20160693.

Navarro-Martín, L., Viñas, J., Ribas, L., Díaz, N., Gutiérrez, A., Di Croce, L., \& Piferrer, F. (2011). DNA Methylation of the Gonadal Aromatase (Cyp19a) Promoter Is Involved in Temperature-Dependent 
Sex Ratio Shifts in the European Sea Bass. PLoS Genet, 7, e1002447.

Near, T. J., Eytan, R. I., Dornburg, A., Kuhn, K. L., Moore, J. A., Davis, M. P., ... Smith, W. L. (2012). Resolution of Ray-Finned Fish Phylogeny and Timing of Diversification. Proceedings of the National Academy of Sciences, 109, 13698-13703.

Nivelle, R., Gennotte, V., Kalala, E. J. K., Ngoc, N. B., Muller, M., Mélard, C., \& Rougeot, C. (2019). Temperature Preference of Nile Tilapia (Oreochromis Niloticus) Juveniles Induces Spontaneous Sex Reversal. PLOS ONE, 14, e0212504.

Nozu, R., \& Nakamura, M. (2015). Cortisol Administration Induces Sex Change from Ovary to Testis in the Protogynous Wrasse, \&lt;B\&gt;\&lt;I\&gt;Halichoeres Trimaculatus\&lt;/I\&gt;\&lt;/B\&gt; Sexual Development, 9, 118-124.

Olivotto, I., \& Geffroy, B. (2017). Clownfish. In Marine Ornamental Species Aquaculture (Calado, R., Olivotto, I., Oliver, M. P., Holt, G. J., eds), pp. 177-199 John Wiley \& Sons, Ltd.

Ortega-Recalde, O., Goikoetxea, A., Hore, T. A., Todd, E. V., \& Gemmell, N. J. (2020). The Genetics and Epigenetics of Sex Change in Fish. Annual Review of Animal Biosciences, 8, null.

Ospina-Álvarez, N., \& Piferrer, F. (2008). Temperature-Dependent Sex Determination in Fish Revisited: Prevalence, a Single Sex Ratio Response Pattern, and Possible Effects of Climate Change. PLoS ONE, 3, e2837.

Patiño, R., Davis, K. B., Schoore, J. E., Uguz, C., Strüssmann, C. A., Parker, N. C., ... Goudie, C. A. (1996). Sex Differentiation of Channel Catfish Gonads: Normal Development and Effects of Temperature. Journal of Experimental Zoology, 276, 209-218.

Piferrer, F., Blázquez, M., Navarro, L., \& González, A. (2005). Genetic, Endocrine, and Environmental Components of Sex Determination and Differentiation in the European Sea Bass (Dicentrarchus Labrax L.). General and Comparative Endocrinology, 142, 102-110.

Piferrer, F., Anastasiadi, D., Valdivieso, A., Sánchez-Baizán, N., Moraleda-Prados, J., \& Ribas, L. (2019). The Model of the Conserved Epigenetic Regulation of Sex. Frontiers in Genetics, 10.

Pompini, M., Buser, A. M., Thali, M. R., Siebenthal, B. A. V., Nusslé, S., Guduff, S., \& Wedekind, C. (2013). Temperature-Induced Sex Reversal Is Not Responsible for Sex-Ratio Distortions in Grayling Thymallus Thymallus or Brown Trout Salmo Trutta. Journal of Fish Biology, 83, 404-411.

Reid, P. C., Hari, R. E., Beaugrand, G., Livingstone, D. M., Marty, C., Straile, D., ... Zhu, Z. (2016). Global Impacts of the 1980s Regime Shift. Global Change Biology, 22, 682-703.

Ribas, L., Liew, W. C., Díaz, N., Sreenivasan, R., Orbán, L., \& Piferrer, F. (2017). Heat-Induced Masculinization in Domesticated Zebrafish Is Family-Specific and Yields a Set of Different Gonadal Transcriptomes. Proceedings of the National Academy of Sciences, 114, E941-E950.

Römer, U., \& Beisenherz, W. (1996). Environmental Determination of Sex in Apistogrammai (Cichlidae) and Two Other Freshwater Fishes (Teleostei). Journal of Fish Biology, 48, 714-725.

Santi, S., Rougeot, C., Toguyeni, A., Gennotte, V., Kebe, I., \& Melard, C. (2017). Temperature Preference and Sex Differentiation in African Catfish, Clarias Gariepinus. Journal of Experimental Zoology Part A: Ecological and Integrative Physiology, 327, 28-37.

Santi, S., Gennotte, V., Toguyeni, A., Mélard, C., Antoine, N., \& Rougeot, C. (2016). Thermosensitivity of the Sex Differentiation Process in the African Catfish, Clarias Gariepinus: Determination of the Thermosensitive Period. Aquaculture, 455, 73-80.

Schreck, C. B., \& Tort, L. (2016). 1 - The Concept of Stress in Fish. In Fish Physiology (Schreck, C. B., Tort, L., Farrell, A. P., Brauner, C. J., eds), Biology of Stress in Fish, pp. 1-34 Academic Press.

Schwanz, L. E., Georges, A., Holleley, C. E., \& Sarre, S. D. (2020). Climate Change, Sex Reversal and Lability of Sex-Determining Systems. Journal of Evolutionary Biology, 33, 270-281.

Selmoni, O. M., Maitre, D., Roux, J., Wilkins, L. G. E., Marques da Cunha, L., Vermeirssen, E. L. M., ... Wedekind, C. (2019). Sex-Specific Changes in Gene Expression in Response to Estrogen Pollution around the Onset of Sex Differentiation in Grayling (Salmonidae). BMC Genomics, 20, 583.

Senior, A. M., Lim, J. N., \& Nakagawa, S. (2012). The Fitness Consequences of Environmental Sex Reversal in Fish: A Quantitative Review. Biological Reviews, 87, 900-911.

Senior, A. M., Johnson, S. L., \& Nakagawa, S. (2016). Sperm Traits of Masculinized Fish Relative to Wild-Type Males: A Systematic Review and Meta-Analyses. Fish and Fisheries, 17, 143-164.

Stölting, K. N., \& Wilson, A. B. (2007). Male Pregnancy in Seahorses and Pipefish: Beyond the Mammalian Model. BioEssays, 29, 884-896.

Strüssmann, C. A., Calsina Cota, J. C., Phonlor, G., Higuchi, H., \& Takashima, F. (1996). Temperature Effects on Sex Differentiation of Two South American Atherinids, Odontesthes Argentinensis and Patagonina Hatcheri. Environmental Biology of Fishes, 47, 143-154. 
Tabata, K. (1995). Reduction of Female Proportion in Lower Growing Fish Separtated from Normal and Feminized Seedlings of Hirame Paralichthys Olivaceus. Fisheries science, 61, 199-201.

Uchida, D., Yamashita, M., Kitano, T., \& Iguchi, T. (2004). An Aromatase Inhibitor or High Water Temperature Induce Oocyte Apoptosis and Depletion of P450 Aromatase Activity in the Gonads of Genetic Female Zebrafish during Sex-Reversal. Comparative Biochemistry and Physiology Part A: Molecular \& Integrative Physiology, 137, 11-20.

Valdivia, K., Jouanno, E., Volff, J.-N., Galiana-Arnoux, D., Guyomard, R., Helary, L., ... Guiguen, Y. (2014). High Temperature Increases the Masculinization Rate of the All-Female (XX) Rainbow Trout "Mal" Population. PLOS ONE, 9, e113355.

Valdivieso, A., Ribas, L., Monleón-Getino, A., Orbán, L., \& Piferrer, F. (2020). Exposure of Zebrafish to Elevated Temperature Induces Sex Ratio Shifts and Alterations in the Testicular Epigenome of Unexposed Offspring. Environmental Research, 109601.

Valenzuela, N., \& Lance, V. A. (2018). Temperature-Dependent Sex Determination in Vertebrates .

Vandeputte, M., \& Piferrer, F. (2018). Genetic and Environmental Components of Sex Determination in the European Sea Bass. In Sex Control in Aquaculture pp. 305-325 John Wiley \& Sons, Ltd.

Walsh, B. S., Parratt, S. R., Hoffmann, A. A., Atkinson, D., Snook, R. R., Bretman, A., \& Price, T. A. R. (2019). The Impact of Climate Change on Fertility. Trends in Ecology \& Evolution, 34, 249-259.

Wang, H., Piferrer, F., \& Chen, S. (2018). Sex Control in Aquaculture. John Wiley \& Sons.

Wang, J., Liu, Y., Jiang, S., Li, W., Gui, L., Zhou, T., ... Chen, L. (2019). Transcriptomic and Epigenomic Alterations of Nile Tilapia Gonads Sexually Reversed by High Temperature. Aquaculture, 508, $167-$ 177.

Warren, D. R., Robinson, J. M., Josephson, D. C., Sheldon, D. R., \& Kraft, C. E. (2012). Elevated Summer Temperatures Delay Spawning and Reduce Redd Construction for Resident Brook Trout (Salvelinus Fontinalis). Global Change Biology, 18, 1804-1811.

Wedekind, C. (2017). Demographic and Genetic Consequences of Disturbed Sex Determination. Phil. Trans. R. Soc. B, 372, 20160326.

Wedekind, C., Evanno, G., Székely, T., Pompini, M., Darbellay, O., \& Guthruf, J. (2013). Persistent Unequal Sex Ratio in a Population of Grayling (Salmonidae) and Possible Role of Temperature Increase. Conservation Biology, 27, 229-234.

Wedekind, C., \& Küng, C. (2010). Shift of Spawning Season and Effects of Climate Warming on Developmental Stages of a Grayling (Salmonidae). Conservation Biology, 24, 1418-1423.

Wen, A. Y., You, F., Sun, P., Li, J., Xu, D. D., Wu, Z. H., Zhang, P. J. (2014). CpG Methylation of Dmrt1 and Cyp19a Promoters in Relation to Their Sexual Dimorphic Expression in the Japanese Flounder Paralichthys Olivaceus. Journal of Fish Biology, 84, 193-205.

Wilkins, L. G. E., Clark, E. S., Farinelli, L., Wedekind, C., \& Fumagalli, L. (2015a). Embryonic Gene Expression of Coregonus Palaea (Whitefish) under Pathogen Stress as Analyzed by High-Throughput RNA-Sequencing. Fish \& Shellfish Immunology, 47, 130-140.

Wilkins, L. G. E., Rogivue, A., Fumagalli, L., \& Wedekind, C. (2015b). Declining Diversity of EggAssociated Bacteria during Development of Naturally Spawned Whitefish Embryos (Coregonus Spp.). Aquatic Sciences, 77, 481-497.

Wilkins, L. G. E., Rogivue, A., Schütz, F., Fumagalli, L., \& Wedekind, C. (2015c). Increased Diversity of Egg-Associated Bacteria on Brown Trout ( Salmo Trutta ) at Elevated Temperatures. Scientific Reports, 5, 1-15.

Wilkins, L. G. E., Fumagalli, L., \& Wedekind, C. (2016). Effects of Host Genetics and Environment on Egg-Associated Microbiotas in Brown Trout (Salmo Trutta). Molecular Ecology, 25, 4930-4945.

Wilkins, L. G. E., Marques da Cunha, L., Menin, L., Ortiz, D., Vocat-Mottier, V., Hobil, M., ... Wedekind, C. (2017). Maternal Allocation of Carotenoids Increases Tolerance to Bacterial Infection in Brown Trout. Oecologia, 185, 351-363.

Wilson, C. A., High, S. K., McCluskey, B. M., Amores, A., Yan, Y., Titus, T. A., ... Postlethwait, J. H. (2014). Wild Sex in Zebrafish: Loss of the Natural Sex Determinant in Domesticated Strains. Genetics, 198, 1291-1308.

Yano, A., Nicol, B., Jouanno, E., Quillet, E., Fostier, A., Guyomard, R., \& Guiguen, Y. (2013). The Sexually Dimorphic on the Y-Chromosome Gene (SdY) Is a Conserved Male-Specific YChromosome Sequence in Many Salmonids. Evolutionary Applications, 6, 486-496.

Zhou, H., Zhuang, Z., Zhang, R., Xu, Q., Liang, Y., Jiang, Z., ... Li, Y. (2019). Temperature-ControlInduced Masculinization in Tiger Puffer Takifugu Rubripes. Journal of Oceanology and Limnology, $37,1125-1135$. 


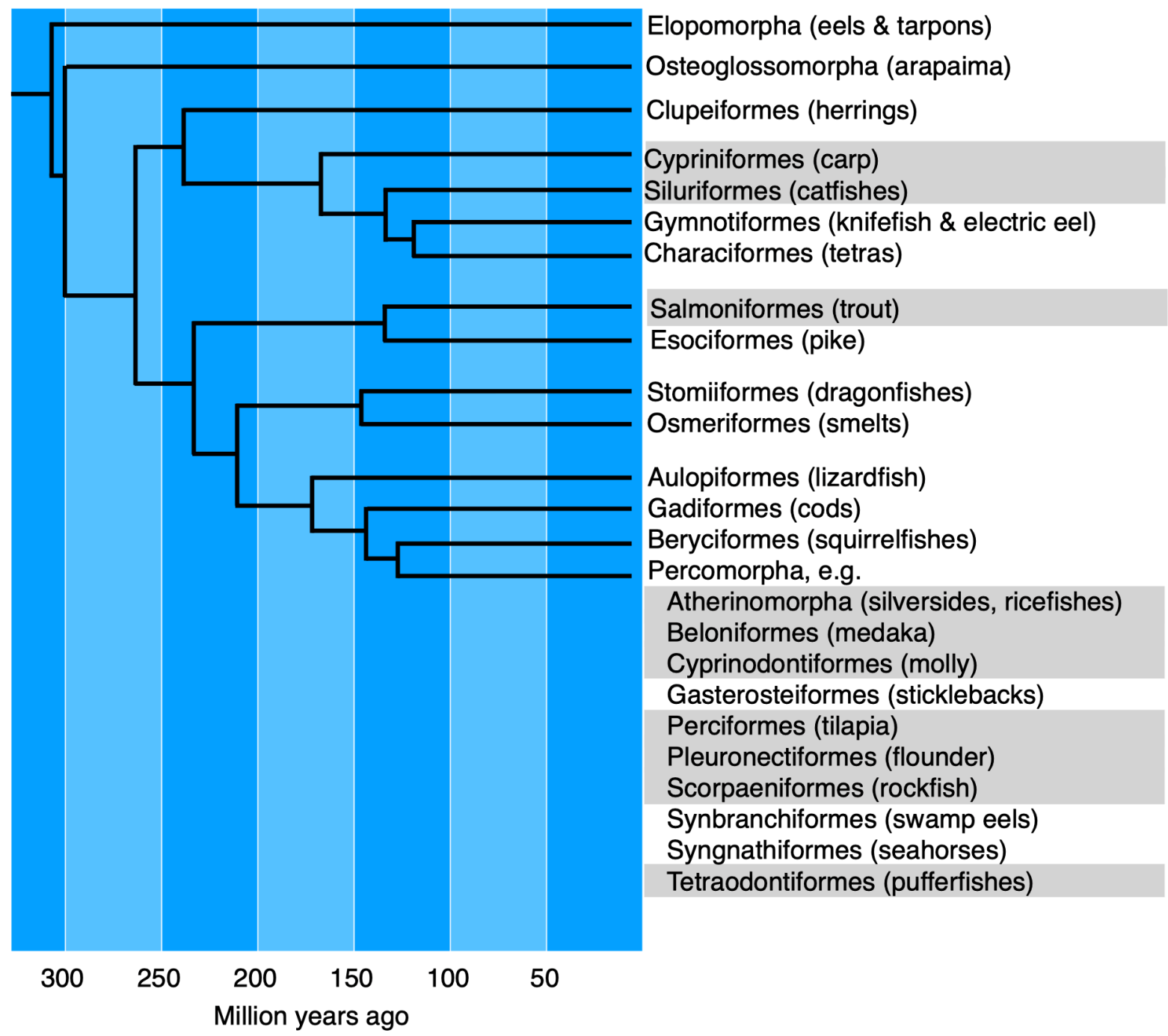

Figure 1. Phylogeny of major orders or superorders of teleost fishes, time-calibrated by Near et al. (2012). Orders with examples of temperature effects on sex determination are highlighted, the parentheses give examples. 
A
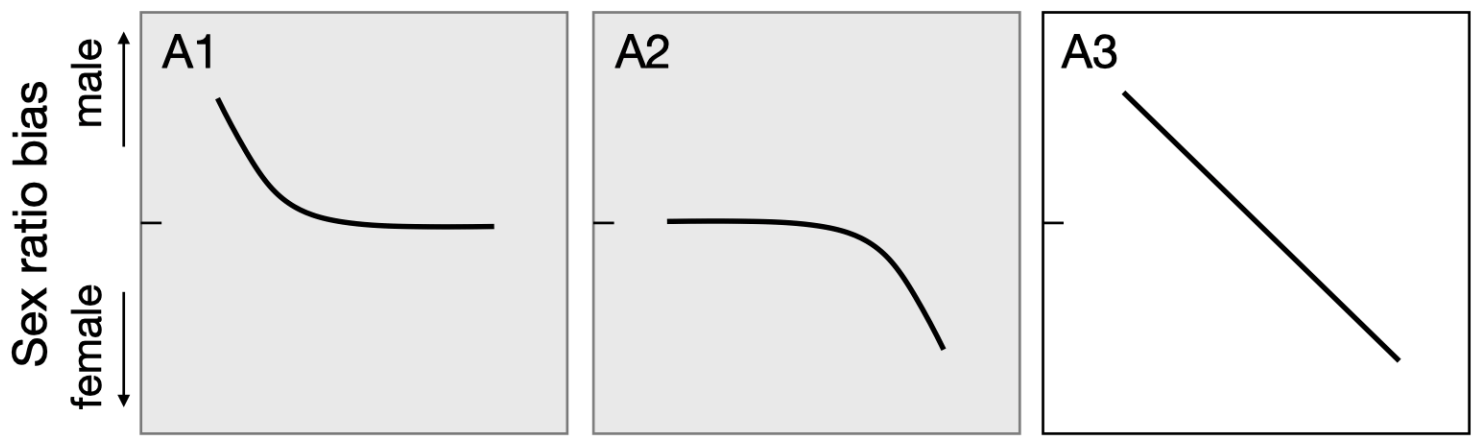

B
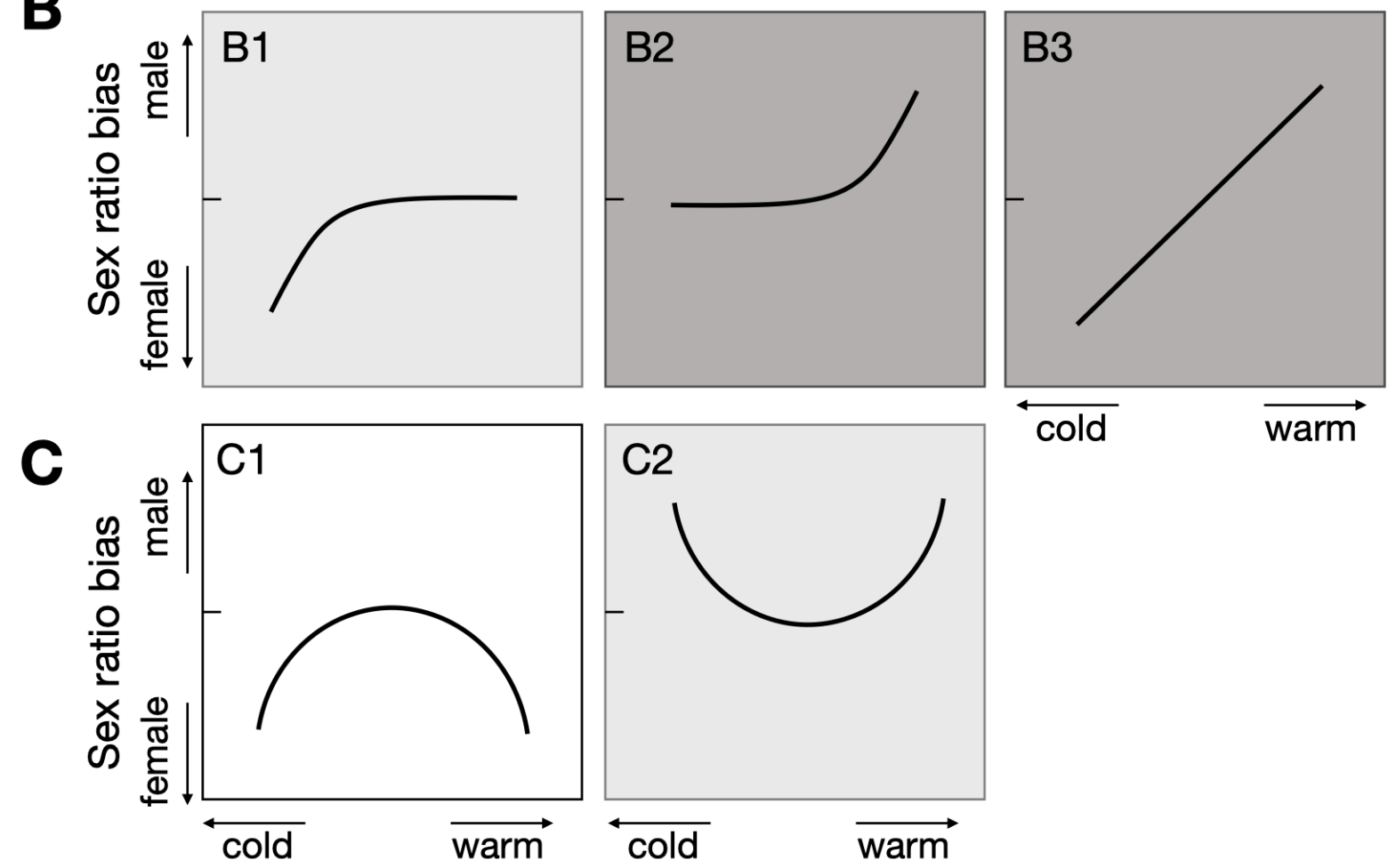

Water temperature

Figure 2. The types of potential temperature effects on shifts in population sex ratio: Decrease (A) or increase (B) in proportion of males with increasing temperature; decrease or increase in proportion of males at extreme temperatures (C). Most observations so far show male biases at high temperature (emphasized in dark grey, examples mentioned in Introduction), but other sex ratio biases have been reported (emphasized in light grey), for example A1: tiger puffer Takifugu rubripes (Zhou et al., 2019), A2: channel catfish Ictalurus punctatus (Patiño et al. 1996), B1 : tidewater silverside Menidia peninsulae (Middaugh \& Hemmer, 1987), C2: southern flounder Paralichthys lethostigma (Luckenbach et al., 2003). 


\section{$\oplus$ Temperature}

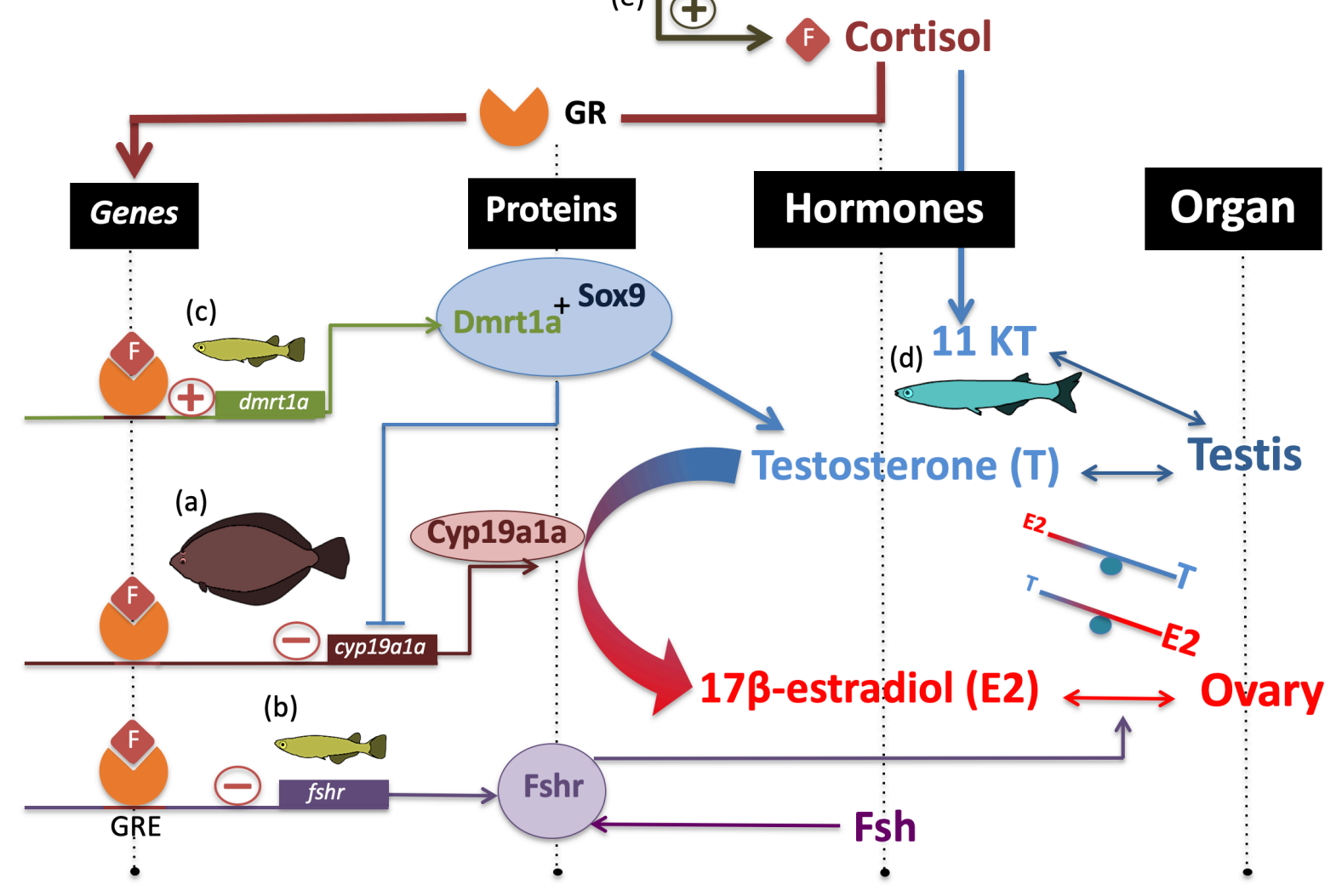

Figure 3. A scheme of how temperature affects sex through cortisol increases in different fish species. a) Yamaguchi et al., 2010 b) Hayashi et al., 2010 c) Adolfi et al., 2019 d) Fernandino et al., 2013 e) Alfonso et al. 2020 (this issue). These various studies indicate that the glucocorticoid receptors (GR)/cortisol association binds to DNA regions known as glucocorticoid response element (GRE) that ARE located in the promoter sequence of different genes: dmrtla or fshr in the medaka and cyp19ala in the olive flounder. This triggers either an up- or down-regulation of downstream genes, which results in a differential translation of proteins involved in sex determination/differentiation or of the related to sex steroid balance. Finally, the undifferentiated gonads exposed to different levelS of sex steroids develop into testis or ovary. More details of the process are provided in the main text. 'Proteins' refers to sex-related proteins. GR: (in fishes the mineralocorticoid receptor is also a cortisol receptor); Fsh: follicle stimulating hormone. Full arrows represent direct link. 


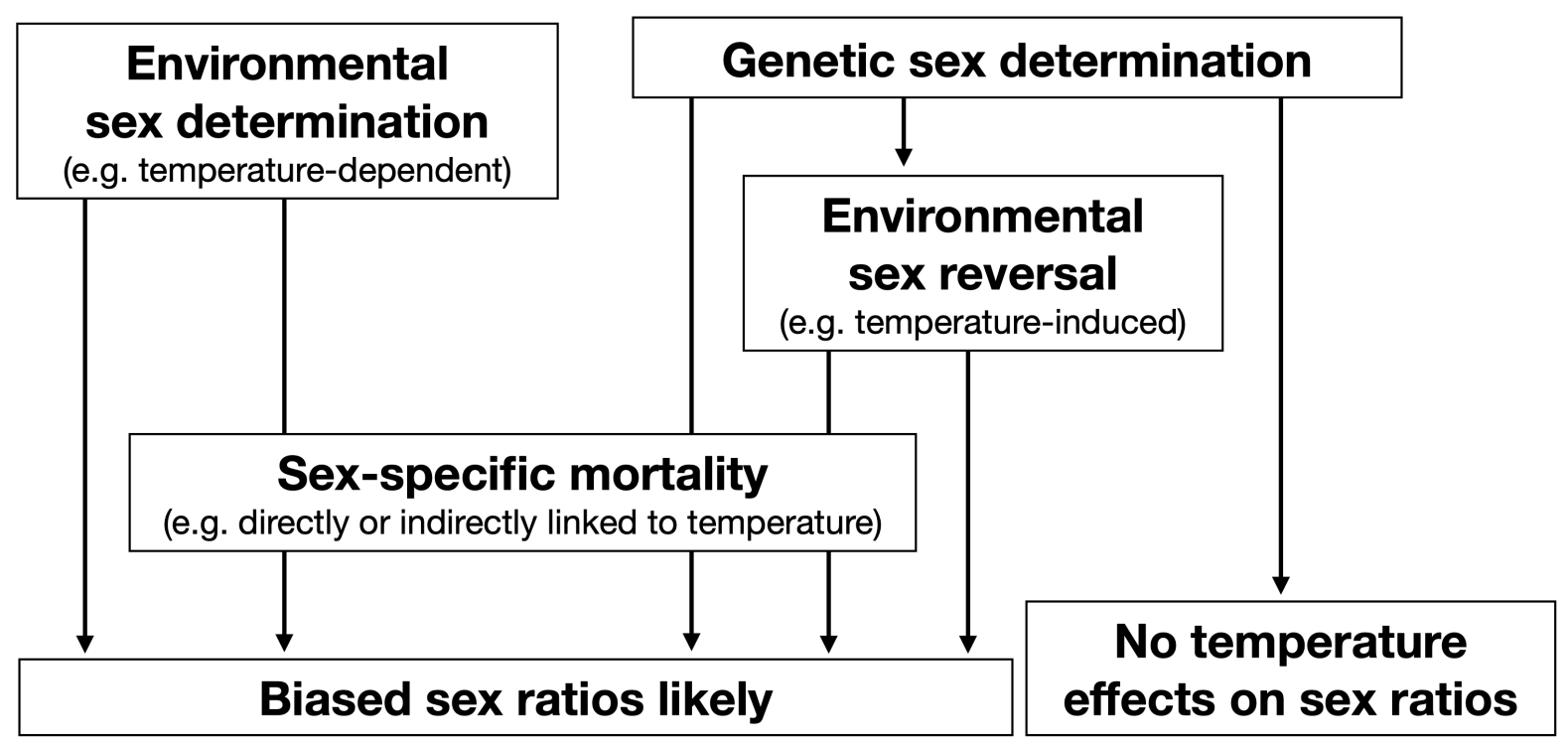

Figure 4. Temperature effects on sex determination and on sex-specific mortality can cause biases in population sex ratios. These temperature effects can vary among families (and potentially cancel each other out at the population level). Further factors that can cause biased population sex ratios or operational sex ratios are temperature-induced and sexspecific changes in, for example, the timing of maturation, migration, spawning behavior, and fertility.

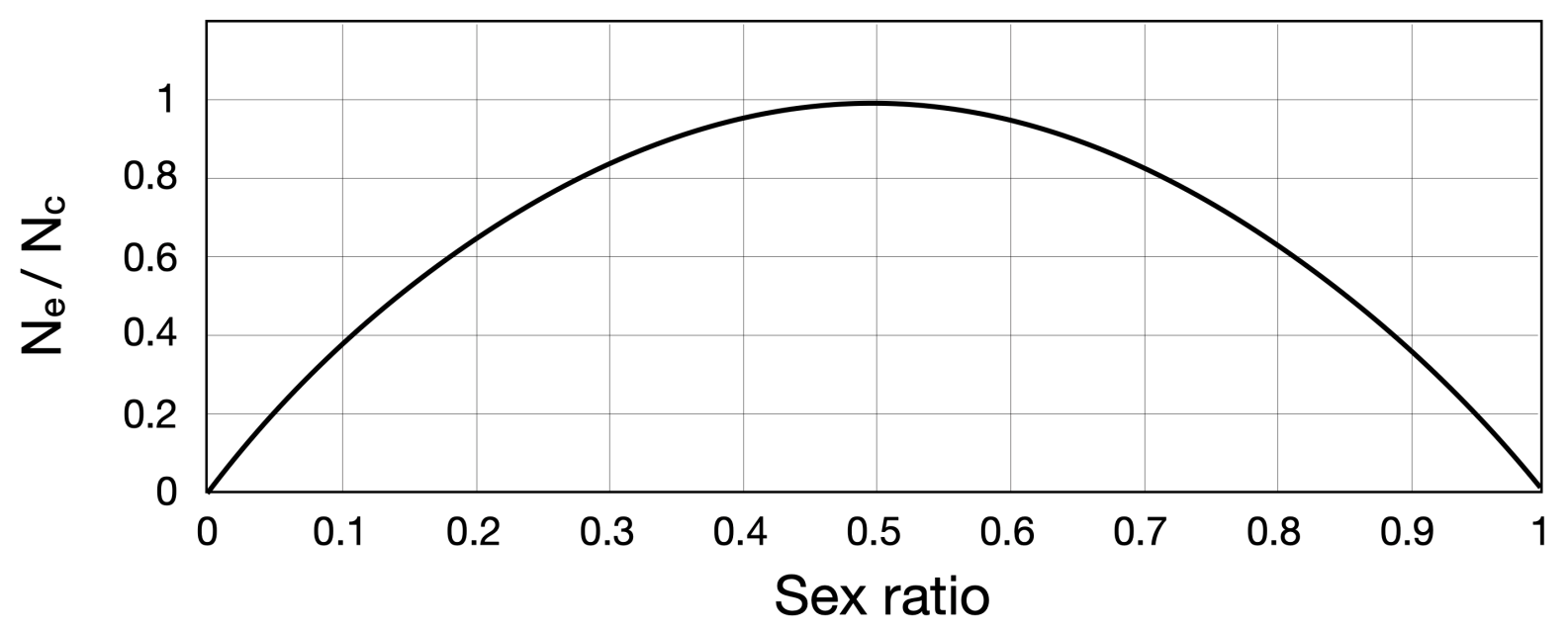

Figure 5. Effect of biased sex ratios, for example due to temperature effects on sex determination, sex-specific mortality, or sex-specific fertility, on genetically effective population size $\left(\mathrm{N}_{\mathrm{e}}\right)$ relative to the census size $\left(\mathrm{N}_{\mathrm{c}}\right)$. 